\title{
Climate change farm based autonomous adaptation measures and its impact on wheat crop productivity in Punjab, Pakistan
}

Dilshad Ahmad ( $\nabla$ dilshad@ciitvehari.edu.pk)

COMSATS University Islamabad, Vehari Campus Pakistan https://orcid.org/0000-0002-3991-805X

Muhammad Afzal

Preston University Islamabad, Pakistan

\section{Research Article}

Keywords: Wheat farmers, Climate risks, Probit model, Punjab, Pakistan

Posted Date: February 9th, 2022

DOI: https://doi.org/10.21203/rs.3.rs-1214354/v1

License: @ (i) This work is licensed under a Creative Commons Attribution 4.0 International License. Read Full License 


\section{Abstract}

Climate induced hazards has increased production threats to agriculture where such environmental risks can significantly reduced by adapting adaptation measures. In farm based adaptation measures specifically the autonomous adaptation aspect has not properly focused particularly in developing countries like Pakistan. This study attempted to investigate on-farm autonomous adaptation (OFAA) measures of wheat farmers to climate change and estimate its impact on wheat yield and total return. This research work used the data of 480 wheat farmer from production based six categorized higher vulnerable districts of Punjab, Pakistan. Probit model was employed to examine adaptation decisions determinants of farmers and Propensity Score Matching used for to investigate the impact of OFAA practices on outcomes of wheat crop. Estimates indicated as wheat farmers to reduce the unfavorable effects of climate change have applied different OFAA strategies such as seed varieties changing, fertilizer management, variations in cultivation dates and management of supplementary irrigated water. Probit model estimates illustrated as climate information access, credit access, ownership of land, off-farm income and ownership of tubewell considered significant determinants regarding adaptation decisions of farmers. Estimates of propensity score matching indicated as farmers those applied almost one OFAA strategy obtained $310 \mathrm{~kg}$ per hectares higher wheat yield as US\$82.75 per hectares return rather than those not applied any adaptation strategies. Adapter wheat farmers applied multiple adaptation strategies obtained higher yield and return rather than adapter farmers used limited adaptation strategies. Results imply as in developing sustainable farmers livelihood, adequate food production, reducing crops variability and climate change adverse impacts it is mandatory to applications of OFAA measures. The study also elaborated as for developing farm-level adaptation there is significant role of climate information, farmers schooling, access of credit and adequate irrigation.

\section{Introduction}

Climate change frequent dynamics in the couple of decades has increased severity and incidence of natural disasters such as flood, landslides, drought, cyclones and earthquakes (Teo et al., 2018; Huong et al., 2019; Martins and Gasalla, 2020; Ahmad and Afzal, 2021). In 21st century, adverse impacts of climate change caused major threats to socioeconomic development which particularly and severely affected the livelihood of rural farmer population (Eckstein et al., 2018; Nerrini et al., 2019; Kreft et al., 2021). Rising global temperature and weather pattern variation due to climate change caused severe losses to overall economic sectors whereas agricultural was hardest hit (Crane et al., 2017; Rasiah et al., 2018; Hussain et al., 2019). In global scenario, world's majority population livelihood directly depends and gains nutritional food from agriculture (Ahmad et al., 2019; Shah et al., 2020) whereas this sector confronted with climatic threats which has alarming implications of global poverty alleviation and food security (Daniell et al., 2017; Amare and Simane, 2018; Ahmad and Afzal, 2020). Climatic threats globally affected agriculture whereas South Asian region considered higher vulnerable in such perspective because of dense population, pitiable adaptive capacities and agro-based economies (Bokhari et al., 2018; Eckstein et al., 2019; Martins and Gasalla, 2020; Hoq et al., 2021). South Asian region is also recognized the super market of natural hazards due to its consecutive occurrence and higher severity which specifically caused destruction of crops and infrastructure (Teo et al., 2018; Ahmad et al., 2019 Kreft et al., 2021). It is forecasted as continuity in rising sequence of temperature will reduce cereal production 10\% till year 2100 particularly in South Asia region (Aggarwal and Sivakumar, 2010; IPCC, 2019; Khan et al., 2020).

In global perspective, Pakistan ranked world 5th climate change affected country due to significant variability of climate change (Eckstein et al., 2018; Kreft et al., 2021). In Pakistan it is estimated to raise $0.5^{\circ} \mathrm{C}$ annually from 1960 which approaches to $3^{\circ} \mathrm{C}$ till year 2100 (Khatri-Chhetri et al., 2019; Khan et al., 2021) as such consecutive raising temperature has increased the occurrence of climate induced hazards such as erratic rains, cropping season variations, biological hazards, droughts and floods (Ahmad and Afzal, 2020; Shah et al., 2020). In the couple of decades Pakistan faced sequence of four deadly floods 2010 to 2014 and from 1990 to 2000 series of severe droughts (PBS, 2017; NDMA, 2019; Ahmad and Afzal, 2021) which consequently raised biological risks and faming communities livelihood become more vulnerable (Shah et al., 2018; Jawid et al., 2019). In last twenty years, the current locust insect's outbreak devastated the country crops which mostly related to regional unpredictability of precipitation and temperature (BOS Punjab, 2020; PBS, 2021). It is estimated as in Pakistan future rainfall change $-0.89 \mathrm{~mm}$ and temperature will raise $+0.24^{\circ} \mathrm{C}$ per decade and climatic parameters cause to significantly variation in current climate (WHO, 2013; Islam and Ghosh, 2021). In the scenario of Punjab province climate change per decade projection estimated as declining in rainfall -3.5mm and rising in temperature $+0.05^{\circ} \mathrm{C}$ causes to increase the large length vulnerabilities to agricultural crops (PMD, 2018; Ahmad et al., 2019; PBS, 2020). 
Pakistan an agrarian economy where almost 70\% population depends on agriculture for their livelihood it provides employment to $38.5 \%$ labor force and shares $19.2 \%$ GDP of the country (PBS, 2021). During the couple of decades because of frequent climatic variations country faced higher yield losses particularly the cereal crops which subsequently raised emerging issue of food security in the country (Shah et al., 2020; PBS, 2020). In cereal crops, wheat is main cereal crop of the country which provides staple food diet to population (Ahmad et al., 2019; PBS, 2020) as Pakistan ranked 8th major wheat producer country in global perspective (FAO, 2019). Wheat crop contributes $1.8 \%$ of GDP and $9.2 \%$ in agriculture value added of the country (PBS, 2020). In crop year of 2020 , wheat was cultivated in 8,805 thousands hectares and produced 25.248 million tonnes with the yields of $2867 \mathrm{~kg}$ per hectares which is relatively lower as other agrarian wheat producing countries (PBS, 2021). In the last couple of decades, Pakistan faced repeated environmental variations such as drought in winter season and climate induced diseases, erratic rains and floods in summer season caused severe losses of crops production (Ahmad et al., 2019; PMD, 2019; Shah et al., 2020). Wheat yield is consecutively declining in Pakistan due to severe climate induced threats such as hail, erratic rain and storm in summer harvesting season and drought in winter season (Abid et al., 2015; Ahmad and Afzal, 2020).

Climate change adaptation is considered as varying farming practices regarding to projected or existing environmental variability to evading possible risks (Rahman and Hickey, 2018; Abid et al., 2020). Adaptation can categorized according to type and nature whereas planned and autonomous are most significant types regarding adaptation measure (Khanal et al., 2018; Khan et al., 2020; Ahmad and Afzal, 2021). Autonomous adaptation deals as farmer responses at farm level in which farmer regarding their considerations and pattern of local climate adapt farm based climate induced adaptation measures (Mersha and van Laerhoven, 2018; Ahmad et al., 2019). Planned adaptation compact with government led involvement wherever State based institutions having the mechanism for designing and application of climate based adaptation measures (Rahman and Hickey, 2019). In the empirical based scenario, planned adaptations have long term significance whereas higher significance about effective application has measured regarding autonomous adaptation where no appropriate facilitation from institutions and government (Leclere et al., 2013; Khanal et al., 2018).

In literature, climate change and agriculture aspect more particularly focused during the couple of decades in global scenario with specifying the climate change mitigation (McCarl and Schneider, 2001; Metz et al., 2007; Duarte et a., 2013; Kabisch et al., 2016; Demski et al., 2017; Lucena et al., 2018; Solan et al., 2020), climate change assessment (Seo and Mendelsohn, 2008; Adger et al., 2009; Iglesias et al., 2011; Zhongming et al., 2012; Pandey et al., 2016; Nakashima and Krupnik, 2018; Nakashima et al., 2018; Abid et al., 2019; Arif et al., 2020; Giri et al., 2020) and climate change adaptation measures (Schlenker and Lobell, 2010; Locatelli et al., 2015; McCarl et al., 2016; Chalise and Naranpanawa,2016; Vermeulen et al., 2018; Day et al., 2019; Cui, 2020; Jørgensen et al., 2020; Chen and Gong, 2021). Some studies in literature also focused climate change adaptation application in various aspects such as risk management through ex-ante and ex-post adaptation (Hou et al., 2018; Abid et al., 2020) where few studies discussed nature of adaptation as planned adaptation and autonomous adaptation (Forsyth and Evans, 2013; Bawakyillenuo et al., 2016; Mersha and van Laerhoven, 2018; Rahman and Hickey, 2019). In literature regarding to higher climate vulnerable country like Pakistan limited research work exists with various aspects such as climatic disaster risk reduction (Shah et al., 2020), climate vulnerability (Khan et al., 2020) and assessment of risk and models of climate risk assessment (Siddiqui et al., 2012; Abid et al., 2016; Ali et al., 2017; Ahmad et al., 2020) whereas no research work in scenario of Pakistan have not addressed the aspect of autonomous adaptation application for local poverty reduction and food security. In developing country like Pakistan where State based institutions are not capable to support farming communities, farming community least resilient and agriculture higher susceptible to climate variation adaptation on farm level and its usefulness have higher significance such aspect need to address. In addressing this research gap this research work paying attention (a) to investigate wheat farmer's on-farm climate change autonomous adaptation strategies (b) to estimate impact of adaptation on wheat crop yield and total return (c) to investigate its applications for local poverty reduction and food security. This study is subdivided in to four segments as introduction illustrated in first segment, second segment discussed material and method. Third segment of the study highlighted results and discussion whereas last segment elaborated the conclusion and suggestions.

\section{Material And Method}

\subsection{Selection of study area}


Punjab province is publicly recognized the land of five rivers, augmented with fertile lands and located in central region of the country (GOP, 2021). Punjab among four provinces of the country more preferably focused for this research because of several considerable bases. Firstly, Punjab is foremost agricultural GDP contributor $52 \%$ and represents $53 \%$ population of the country (PBS, 2020). Secondly, Punjab by producing $3 / 4$ of country's cereals production is known food basket of the country (GOP, 2021). Thirdly, Punjab produces $77 \%$ wheat of the country (BOS Punjab, 2020) whereas currently facing consecutive and significant yield reduction owing to induced factors of climate change. Lastly, wheat production is more susceptible in the region due to consecutive increase in erratic rainfall, rising temperature and frequent hailstorms in recent decades (PBS, 2021). This scenario has severe threat for livelihood of millions of wheat farmers' households and food security relying for their employment and nutrition in the region. Kharif and Rabi are two major cropping seasons comprising with major and minor crops (BOS Punjab, 2019). Based on share of province in wheat production six districts were chosen with various wheat production based categorizations. In scenario of wheat production, Dera Ghazi Khan and Layyah from low wheat producing districts, Muzaffargarh and Vehari from medium while Rahim Yar Khan and Bahawalnagar from high wheat producing districts were purposively chosen for the study as indicated in figure 1(BOS Punjab, 2021). In the study, all six selected districts, risk variations experience, socioeconomic, geographical, climatic and structural characteristics were documented. In provincial environment climatic variation were estimated as cold in winter and hot in summer having the average temperature of $33.9^{\circ} \mathrm{C}$ in summer and average temperature of $8.7^{\circ} \mathrm{C}$ in winter (PMD, 2019). In Punjab, rainfall disperse pattern was estimated where $68 \%$ erratic and routine rainfall mostly expected in monsoon season (PMD, 2019; BOS Punjab, 2020). Major cash (sugarcane and cotton) and cereals crops (wheat, rice and maize) major share is produced in Punjab province which severely affected from climate induced factors (PBS, 2021).

[Figure 1]

\subsection{Data collection and sampling framework}

In sample selection of wheat growers from the study area multistage sampling method was used by involving random selection and stratified approach. In the first stage, Punjab more preferably considered because of higher wheat production province in the country. In the second stage, in using the stratified sampling approach six districts were chosen according to categorized low, medium and high wheat producing areas of Punjab. In particular, districts were categorized in province such as low wheat producing zone (below 600,000 tonnes), medium wheat producing zone (600,000 to 900,000 tonnes) and high wheat producing zone (above 900,000tonnes). In each categorized wheat production zone, two districts were randomly selected in the third stage. In fourth stage, two tehsils from each district were randomly chosen and from each tehsil two union councils were randomly chosen. In the last stage, from each union council two villages were randomly chosen and ten wheat farmers were randomly preferred for data collection comprising 480 total wheat farmer from study area. From each province eighty wheat farmers were interviewed as sampling framework illustrated in Table 1.

\section{[Table 1]}

In the study area, a well-structured questionnaire was applied for face to face interview and data collection from sample household's wheat farmers. To ensuring the accuracy and relevancy of the data a pre-tested survey was conducted prior to collecting the data from study area. Farmers farming practices, socioeconomic characteristics, farm outcomes related to production outcomes and adaptation practices were main feathers included in the questionnaire. Author himself and four enumerators the students of COMSATS University Vehari prior trained for data collection in the study area. Data collection regarding farmer's response about wheat crop outcomes and adaptation practices and data collected from July 2020 to October 2020. In the scenario of study objectives and usage of collected data farmers were well informed and motivated to participate in data collection with accuracy of information. Farmers involve themselves warmly about data collection questionnaire and 27 participants refused to take part which were replaced to others farmers from study area.

\subsection{Empirical framework}

\subsubsection{OFAA evaluation impact on wheat productivity}

Crop return and production is feasible to increase through using the effective adaptation measures. In estimating the adaptation impact on wheat production, wheat farmers were firstly categorized in to two types' non-adapter and adapter farmers. Non-adapter were considered those farmers who have not applied any OFAA adaptation measure and adapter those who at least applied single 
adaptation measure for wheat crop to reduce climate change severity. In such estimation, in the Table 3 there was conducted the mean contrast for revealing significant difference about return and yield of wheat crop between non-adapter and adaptation measures adapter farmers. In the meantime, attributes of farm related and socioeconomic characteristics also varieties in nonadapter and adapter wheat farmers as adapter farmers more access of institutions services and resources rather than others. On the basis of selection biased likelihood such type of empirical results are not adequate to measure the impact of adaptation on wheat return and yield (Abid et al., 2016; Ali et al., 2017; Ahmad et al., 2019). Consequently, it considered critical to undertake the matter selection bias to accurately measure adaptation impact on wheat return and yield.

In literature, selection bias issue tried to minimize in mostly studies tackled with application of different methods such as endogenous switching regression (ESR), approach of instrumental variable (IV) and two-step Heckman test models (Khan et al., 2018; Ahmad and Afzal, 2020). Furthermore, such methods have some limitations in applications such as Heckman method addresses only the internal factor of normal distribution whereas endogenous switching regression (ESR) and approach of instrumental variable (IV) need to applicable instrumental variables about treatment equation to measuring the influence as considered the demanding to identify in the estimation investigation (Heckman and Vytlacil, 2007; Abid et al., 2016). In considering the significance and nature of this study, propensity score matching (PSM) method is applied in this study for estimating the impact of OFAA on wheat yield.

\subsubsection{Propensity score matching (PSM)}

In resolving the issue of selection bias in the model, method of propensity score matching is mostly applied in most of the studies. Concerning the limitations of functional form, unobserved attributes of normal distribution and for treatment equation instrumental variables in the methods of instrumental variable (IV), Heckman and ordinary least square (OLS) whereas propensity score matching (PSM) method has no such limit (Caliendo and Kopeinig, 2008; Rubin, 2015;Ahmad et al., 2019). In the method of propensity score matching on the basis of treatment variable usage and adoption pattern sample is categorized in to two types such adapter as treatment group and non-adapter as controlled group (Dehejia and Wahba, 2002). This study illustrated as those farmers adopted at least single adaption measure indicated as treatment variable (adapter) whereas farmers those not used any adaptation measure elaborated as controlled group (non-adapters). Observed socioeconomic factors are required in the method of propensity score matching (PSM) to match control group and the treatment for estimating the treatment casual impact.

Taking into consideration the pre adaption in scenario of visible threat, the method of propensity score matching can be observed as provisional probability about adaptation of farmer to climate change. Related to the conditional independence assumption the method of propensity score matching constructs the statistical contrasts groups through matching adapter and non-adapter related to their forecasted probabilities of adoption to climate change (Frolich, 2007; Caliendo and Kopeinig, 2008; Froehlich and Al-Saidi, 2017). Propensity score matching (PSM) equation as illustrated below

$p\left(X_{i k}\right)=\operatorname{Pr} .\left[U_{i}=1 \mid X_{i k}\right](1)$

In the above equation propensity score elaborated as $\mathrm{p}$ whereas $\mathrm{X}_{\mathrm{ik}}$ indicated the observable attributes, whereas pr as adaptation probability to climate change $\mathrm{U}_{\mathrm{i}}$. There is similar conditional to distribution regarding to non-adapter and adapter in the model of propensity score matching (Frolich, 2007;Thavaneswaran and Lix, 2008).

In measuring the treatment impact on variables outcomes propensity score matching estimation engaged in to five stages. In the first stage, related to theoretical assumptions initially selected the list of observable covariates (socioeconomic threats of farmers) for pre-testing. Secondly, propensity score or probabilities are estimated through observable covariates of regressing related to outcome variables (adaptation determinants) (Ali and Abdulai, 2010). In the third stage, matching method is applied to anticipated propensity score matching of non-adapter and adapter (Kassie et al., 2011). Treatment casual effect (adaptation) is estimated the variables outcome (wheat yield) in the fourth stage (Rubin, 2001). In the last stage, propensity score evaluation estimation is finalized to check estimation accuracy (Frolich, 2007; Caliendo and Kopeinig, 2008).

\subsubsection{Observable covariates selection}

In agriculture adaptation decisions of farmers are mostly affected by their socioeconomic feathers as empirically investigated in multiple studies (Bryan et al., 2013; Alam et al., 2017; Khanal et al., 2018). Regarding the evidence in literature, data availability and 
nature of study variables in number fifteen were chosen as covariates observable hypothesized regarding farmers decision influence related to climate change strategies adoption. Attributes of institutional services, farm status, farmers socioeconomic characteristics were chosen as observable covariates. In Table 2, list with details of observable covariates of farmers, with measurement unit and description has elaborated. Explanatory variables impact on adaptation decisions with expected direction indicated with the associated sign.

[Table 2]

\subsubsection{Wheat yield adaptation casual impact}

Adaptation (treatment) casual impact on wheat crop yield is estimated on the treated average treatment effect (ATE) and average treatment effect on treated (ATT). Average treatment effect (ATE) reports on average treatment effect on variable outcome in on the whole population whereas ATT refers influence on treatment related to outcome variables among respondents that were treated (treatment matched and controlled respondents). The ATE impact can be reported as below equation

$$
t_{U i=1}=E\left(t \backslash U_{i}=1\right)=E\left(Y_{1} \backslash U_{i}=1\right)-\left(Y_{2} \backslash U_{I}=2\right)(2)
$$

In above equation, in population average treatment effect (ATE) indicated as $t$, control group as $Y_{2}$ and treatment as $Y_{1}$ which is this study related to non-adapter and adapter wheat growers. In such scenario as indicated prior ATE, $E\left(t / U_{i}=1\right)$ do not directly observed through estimating difference $E\left(Y_{1} / U_{i}=1\right)-\left(Y_{2} / U_{i}=2\right)$ as estimates may be biased. Furthermore, ATT can be observed that illustrates the precise estimates after contrasting the treatment and controlled groups. Average treatment effect on treated (ATT) as illustrated in the equation below

$T=E\left\{Y_{1}-Y_{2} \mid U_{i}=1\right\}=E \llbracket E\left\{Y_{1}-Y_{2} \mid U_{i}=1, p(X)\right\} \square=E\left[E\left\{\left(Y_{2} \mid U_{i}=1, p(X)\right\}-E\left\{Y_{2} \mid U_{i}=2, p(X)\right\} \mid U_{i}=2\right](3)\right.$

In above equation, ATT reported as notion $T$ whereas $p(X)$ as after calculated propensity score. In sequence of calculating the $p$ score, respondents were chosen from control and treatment group on the basis of their alike visible traits by applying the procedure of nearest neighbor matching (NNM). Non-adapters and adapters considered the partners this method through similarities matching in socioeconomic profile of farmers. Lastly, respondents separate groups are generated (unmatched and matched). Furthermore, outcome difference is subtracted by ATT in the matched groups which show the bias section minimal chances (Rubin, 2001; Dehejia and Wahba, 2002).

\section{Results And Discussion}

\subsection{Farmers socioeconomic characteristics descriptive statistics}

Climate change strategies non-adapter, adapter differences and pooled sample farm base and socioeconomic characteristics mean values illustrated in Table 3. In study area majority of wheat farmers $78 \%(374)$ adopted OFAA climate change adaptation measures whereas adapter were relatively younger (45 years), higher schooling (8years) rather than average schooling (7years) and age (48 years) in sample area. Adapter farmers have higher household size (8members) and primary occupation of agriculture (88\%) rather than average household size (7members) and primary occupation (75\%) in study area. Almost $49 \%$ non-adapter farmer's considered agriculture primary source of family income so less conscious to manage adaptation rather than adapter farmer. In study area, average land holding (7acres) and $90 \%$ farmers having land ownership whereas adapter farmers have higher land holding (9acres) and $97 \%$ were owner of land illustrating as adapter have higher ownership and holding land than non-adapter farmers. In study area, limited irrigation $13.7 \%$ feasible with canal water whereas $86.3 \%$ managed by farmer through tubewell because of that majority $90 \%$ of adapter farmers having ownership of tubewell rather than $32 \%$ non-adapter farmers. These illustrations indicated as water supply enhances the farmer's capacity of managing climate risks of wheat crop such as in winter shortage of water is managed through tubewell water supply.

[Table 3] 
In study area, adapter farmers considered more resourceful regarding assets as holding average 8animals and farm income almost 49 thousands monthly higher than non-adapter with livestock (4.32 animals) and 24 thousands monthly income. Climate

information access, advisory services and credit access considered significant variables regarding institutional services in the study area. Information accessed through formal and informal sources whereas farm based formal sources organizations/institutions by private and public considered more feasible in this study. Estimates illustrated as farmers have higher access of climate change information $60 \%$ and advisory services $57 \%$ rather than credit access $36 \%$ because of higher advancements in technologies such as mobile phones and internet access. Mostly organizations and institutions provide advisory services and climate information through SMS/WhatsApp applications which becomes more feasible for farmers (Khan et al., 2020; Ahmad and Afzal, 2021). These results illustrated as adapter farmers as contrast to non-adapter farmers more resourceful regarding assets because of higher more access of information and higher income due to more consideration regarding climate change adaptations and access higher yield of crops (Zhai et al., 2018).

\subsection{Farmer adapted OFAA strategies}

In the study area to overcoming the climate change risks farmers applied multiple OFAA adaptation strategies as particularly indicated in the figure 2. Overall wheat farmers more specifically focused OFAA seed variety changing (73\%), managing fertilizer $(67 \%)$, strategies supplementary irrigation (64\%), irrigation time changing (61\%), variation of planting and harvesting (56\%) and resizing plots $(51 \%)$. Such estimate illustrated as majority of wheat farmers prioritized changing in usage of seed varieties having water resistance and weather efficient to coping climate change severe effects and less vulnerable to environmental variation. These climate smart varieties having higher resistance to climate severity and induced insects more feasible measure to higher wheat yield as these finding are consistent to studies of Arunrat et al., (2017), Ahmad et al., (2019) and Sertse et al., (2021). Managing fertilizer another significant measure from study area farmers because adequate and timely provision of fertilizer causes to enhances resistance of wheat crop regarding climate variation and appropriate growth of wheat crop as finding is in line with the study of Ahmad and Afzal, (2020). Adequate supply of supplementary irrigation through tubewell to wheat crop in winter season when canal water is not available for irrigation such adaptation measure causes to enhance wheat yield. These estimates are alike with the studies of Abid et al., (2016), Ahmad et al., 2019 and Shah et al., (2020).

[Figure 2]

Furthermore, irrigation variation is another application of water smart strategy consider to use for reducing water requirement of crop mostly indicated as avoid irrigation usage when climate conditions not feasible for irrigation to crop. Climate smart water strategy more significant measures regarding irrigation usage to crop as these findings are alike with the study of Ahmad et al., (2019). Wheat crop cultivation and harvesting altering strategy is mostly induced by local climate variation pattern. Local based climate-induced patterns based strategy of cultivation and harvesting of wheat crop common strategy measure mostly applied by local farmers as conclusions are consistent with research work of Alauddin and Sarker, (2014), Abid et al., (2016) and Khanal et al., (2018). Resizing plots considered the more feasible measure about climate based effects of water shortage. Extension of plots within the acres reported the resizing plots when cultivating various crops in the limited cultivated area whereas such practices causes to more labor cost, irrigation cost, issues of land leveling and time consuming as compared to large plot sizes. These conclusions are in contrast with the study of Arunrat et al., (2017) and Amare et al., (2018).

Farmers from higher and medium wheat production areas more preferably focused the changing crop varieties, managing fertilizer and supplementary irrigation climate smart adaptation strategies whereas low wheat production farmers preferred to plot resizing, changing irrigation time and harvesting and cultivation changing. Adapted based strategies measures of wheat farmers were classified in to four categorizes as higher adapter (applied $>4$ adaptation measures), medium adapter (applied 3 or 4 adaptation measures) small adapter (applied 2 adaptation measures) and non-adapter (not applied any adaptation measure) for assessing diversification application measures. Majority of farmers (34\%) were higher adapter, (28\%) medium adapter and (16\%) small adapter as illustrated in figure 3 illustrating as majority of wheat farmers in the study area have applied multiple adaptation measures to climate change. Almost one-fifth $(22 \%)$ wheat farmers in the study area not focused any climate-induced adaptation measure in the study area. Higher frequency of climate-induced non-adapter and small adapter was estimated in the low production region whereas majority of medium and high adapter farmers belong to high and medium wheat production region. These estimates indicated as in low yield districts farmers having limited diversification adaptations measures whereas higher 
[Figure 3]

\subsection{Adaptation impact on wheat crop yield and return with cost-benefit analysis}

Adapter and non-adapter wheat crop average outcomes comparison illustrated with major differences of wheat yield and return of total crop as indicated in Table 3. Significant variation regarding non-adapter and adapter estimated related to input cost that inspires to prerequisite the analysis of cost benefit. Moreover, for estimating the diversification adaptation impact on outcome of crop, comparison was estimated means of wheat yield, cost of total input, return of total crop and gains of total profit in four categorized farmers groups and generated the results. Wheat farmers were categorized in to four groups for estimating profitability across intensity of adaptation as such measure were taken for estimating adaptation profitability in the research work of Arfanuzzaman et al., (2021).

[Figure 4]

In study area among various types of climate induced strategies adapter farmers the mean (maund per acre) of wheat yield and total return illustrated in figure 4 and 5 . Estimates indicated as wheat crop yield and total return per acre increased from small to medium and higher adapter because higher intensity of adaptation strategies increases yield of wheat production and total return. Remarkably, more prevalent increasing trend related to districts of higher production zone that is the reason of higher adaptive capacity to application multiple adaptation strategies. Another reason is that farmers in high yield region having higher financial resources so allocate additional financial resources for crop inputs. Additional resources allocation for farm inputs particularly based on adaptation of diversification causes ultimately return their input cost.

[Figure 5]

\subsection{Estimates of Propensity Score Matching (PSM) analysis}

Non-adapter and adapter socioeconomics characteristics descriptive statistics indicated the major difference in their access of institutional services, resources and incomes that illustrated the likelihood of affect of these features on their outcome of farm. Therefore, to overcome the biases of such external and internal factors the propensity score matching approach applied to estimation the causal influence of adaptation on outcome of crop. In the section of methodology illustrated as PSM initiates with propensity score estimation by application of regression analysis.

\subsubsection{Propensity score estimation by application of probit regression}

Probit regression estimates indicated as farmer's access of institutional services, income and farm size prominently affects their decisions to climate change adaptation as indicated in Table 4. In particularly, farmer's primary occupation, landholding, livestock and irrigation ownership sources indicated positive and significant whereas income of farm illustrated negative and significant association with adaptation decisions. Estimates of marginal effect additionally illustrated increase in animal one unit in livestock raises possibility to adapt climate change $2.9 \%$ and land size one acre increase possibility to adapt climate change $2.7 \%$. Such of these results illustrated as farmers with higher herd size and farm land highly considered in adaptation to climate change as these results are consistent with the studies of Alauddin and Sarker, (2014), Abid et al., 2016), Zhai et al., (2018). Such measures makes feasible with more farm assets that capable them to application of different farm management strategies for climate change adaption. Availability of higher livestock highlights likelihood of plentiful availability of organic fertilizer that causes to facilitate farmers to application of fertilizer-induced adaptation approaches. Livestock also considered reserve capital of farmer in condition of emergency, mostly utilized as selling it for protect their livelihood from climate change severe affects (Ahmad et al., 2019; Sertse et al., 2021). Land ownership coefficient is negative and insignificant indicating as compared to owner, tenant's farmers higher motivated in application of climate change measures. Such scenario could be due to some significant factors such as land rent pressure, induces tenants to application of climate change measures for higher earning to fulfill the land rent additional cost.

[Table 4]

Page $8 / 23$ 
In farming practices irrigation access through canal and tubewell considered more essential factor regarding wheat cultivation as illustrated the more positive and significant association with farmer decisions of adaptations. Estimates of marginal effect indicated as wheat farmers with own tubewell irrigation access implement $19 \%$ more climate induced adaption measures rather than those farmers having no own irrigation access. In winter season shortage of irrigation water adversely effects wheat crop yield so adequate irrigation water access to wheat crop through tubewell considered main climate change adaption strategy for higher yield and coping severe effects of climate change as results are consistent with the research work of Alauddin and Sarker, (2014) and Ahmad et al., (2019). Adaptation decisions of farmers have considerably influenced by farmers off-farm and farm based income. In the scenario of adaptation decisions, off-farm income illustrated positive and significant whereas farm based income indicated negative and significant association. Farm based negative influence highlighted that farmers have lesser possibility of adaptation while increased farm based income. The reasons may be as farmers having higher farm assets and wealth less worried about climate dynamics regarding wheat yield losses and having no motivation to climate based adaptation strategies as findings are similar with the study of Zhai et al., (2018) and in contrast with the study of Joshi et al., (2017) and Ahmad et al., (2019).

Adaptation behaviour of farmer is prominently influenced by institutional support as estimates of the study illustrated positive and significant effect of credit access on farm based climate change adaptation measures. Marginal effect results indicated as farmers having access of credit having $25 \%$ higher possibility of using climate induced adaption measures rather than those farmers having no access of farming credit. The reason is that the financial support builds up confidence level of farmer such as in drought shocks and temperature shocks credit capable farmers to final major measure about farm based management strategies which causes to minimize climate change adverse effects regarding wheat crop. These results are similar with the studies of Alam et al., (2016), Ullah et al., (2018) and Ahmad and Afzal, (2020). Estimates indicated the positive and significant coefficient of advisory services illustrating as crucial role of advisory services in wheat farmers adaptation of climate change strategies. Marginal effect values elaborated as farmers having the access of advisory services $28 \%$ more probably to adapt climate change strategies in contrast to farmer have no access of advisory services. Agro-based advisory services lead and facilitates farmers to protect weather variation yield losses through late or early cultivation and climate smart practices as these conclusions are in line with the studies of Khan et al., (2019), Ahmad et al., (2019) and Mahmood et al., (2021). Climate based information with positive and significant coefficient indicated as farmer's familiarity about weather, increases farmers becomes more motivated to adaptation of climate based measures. Marginal effect estimates illustrated as wheat farmers those having access of climate change information from agricultural and metrological official's 35\% higher likelihood to adopting climate based adaptation measures as these conclusions are consistent with the studies of Ahmad and Afzal, (2020) and Khan et al., (2021).

\subsubsection{Adaptation causal effect on wheat crop yield and return}

Propensity score was firstly estimated and then NNM matching technique was applied to estimate the casual influence of adaptation (treatment) on non-adapter (control) and adapter (treated) group. Table 5 indicated the influence of treatment on control and treated groups illustrating the values of variables outcome wheat crop yield and total return prior ATE and propensity score (ATT) post matching scenario. Farmers prior matching their internal and external factors known unmatched (observable covariates) also refers in population Average Treatment Effect (ATE) whereas Average treatment effect on treated denoted as (ATT). In regard the estimates of propensity score matching (PSM), Farmers measures of adaptation has largely raised wheat crop yield and total return as the values of ATE indicated an raise of 9.43 maund/per acre and $931.68 \mathrm{~kg}$ per hectares in wheat yield from of adapter which caused wheat farmers rising total wheat crop return PKRs 18396 per acre and US\$278.41 per hectares.

\section{[Table 5]}

In the same scenario ATT has also reported as treatment group also obtained raised wheat yield crop 3.14 maunds per acre and $310.23 \mathrm{~kg}$ per acre whereas wheat crop total return PKRs 6927 per acre and US\$82.75 per hectares as contrast to controlled groups. ATT lower value is because of potential bias reduction which affects impact of adaptation on wheat yield. ATT illustrated that adapter farmers regardless of their socioeconomic status mostly raised wheat yield and obtained higher total wheat crop return rather than non-adapter wheat farmers in the study area. Adaptations measures reduces the severe impacts of climate change also positive and significantly influences the wheat crop yield and total wheat crop return as empirically justified from these estimates in this study. These results are in line with the studies of Thaler et al., (2012), Huang et al., (2015), Ali and Erenstein, (2017), Khanal et al., (2018) and Ahmad et al., (2020). In such scenario in the region or country where millions of households population depends on 
wheat crop for nutrition need and livelihood adaptation measures needs to higher priority for avoiding wheat yield losses and coping adverse impacts of climate change.

\subsubsection{Propensity score evaluation}

In the scenario of estimating casual influence of treatment on variables outcomes it is prerequisite to evaluate results adequacy. In such method, firstly values of $p>c h i^{2}, L R c^{2}{ }^{2}$ and Pseudo- $R^{2}$ were estimated after and before matching the $p$-score $p(X)$. In Table 6 , statistics regarding test illustrated that values of $\mathrm{p}>\mathrm{chi}^{2}, \mathrm{LR} \mathrm{chi}^{2}$ and Pseudo- $\mathrm{R}^{2}$ significantly decreased afterward matching propensity score of respondents. Subsequently, median and mean biases also estimated to evaluate the results adequacy in term of reducing biases of selection.

[Table 6]

Estimates illustrated median biases reduced 59 to $7 \%$ and mean biases reduced from 64 to $10 \%$ elaborating significant reduced bias of external and internal covariates. On the basis of such indicators it can be summarized as estimates of propensity score matching have precisely evaluated treatment (adaptation) impact on farmers outcomes (wheat yield) despite of inherited variations in socioeconomic characteristics of farmers (Rubin, 2001; Ali and Abdulai, 2010; Ahmad et al., 2019). Biased reduction detailed description illustrated in Table 7 as given below.

[Table 7]

\section{Conclusion And Suggestions}

In Pakistan millions of households livelihood and nutrition based on wheat cultivation whereas in the current decade notable decline in wheat crop production estimated because of severe climate change-induced factors such as erratic rains, dynamic temperature and extreme natural events. In the region, wheat productivity can mitigated from climate-induce severe impacts by implementing on-farm autonomous adaptations (OFAA). This study attempted to investigate farmers OFAA strategies and evaluated their impact on wheat crop production and its returns by application of collect data from production based lower, medium and higher categorized six districts of Punjab, Pakistan. Changing seed varieties, farm resizing, irrigation application time variation, management of fertilizer, wheat cultivation dates changes and application of supplementary irrigation indicated significant farmers OFAA strategies as implemented by farmers in the study area. Non-adapter and adapter wheat farmers, wheat crop yield and total return was compared and estimates illustrated adapter farmers having higher wheat yield and total return because of application the climate-induced OFAA strategies. Propensity score matching (PSM) approach was also employed for statistical comparison of non-adapter and adapter related to observational base selection bias. Propensity score matching estimates indicated adapter farmers implementing climate change measures regardless of their socioeconomic variations still obtained higher wheat yield 3.14 maunds per acre and $310.23 \mathrm{~kg}$ per hectares whereas wheat crop total return PKRs 6927 per acre and US\$82.75 per hectares rather than non-adapter farmers. Farm feathers and socioeconomic characteristics significantly influence farmer's decisions of OFAA adaption strategies. Livestock procession, irrigation sources ownership, agriculture as primary occupation, farm size, farm advisory services and credit access illustrated positive and significant relationship with adaptation decisions of farmers.

On-farm autonomous adaptations, positive impact on farmers income and wheat yield has significant implications in reduction of Pakistan financial and nutritional poverty because majority poverty-deprived population inhabited in rural areas of country. In scenario of wheat crop vulnerability, applications of OFAA measures significantly raised wheat crop yield so in future possible losses due to climatic risks can overcome thorough implying OFAA strategies. In farm level, long term effects tackle through planned adaptation measures whereas farm level sudden responses can effectively meet and feasible through autonomous adaptation measures. More specifically in agro-based developing economies like Pakistan, autonomous adaptation has higher feasibility where limited interventions regarding policy level and institutions based acknowledged about planned adaptations. Furthermore, autonomous adaptations in limited efforts may develop resilience and adaptive capacity of marginalized and resource-poor farming groups against climate based hazards. Research findings may guide the policy makers, future researchers and climate governance practitioners to developing framework, adaptation policy and vulnerability modeling. These estimates are limited to Punjab province wheat crop similar regions and countries may also attain implications for evaluate farm level adaptation efficiency and formulating to managing risk based policies. This study has some significant limitations such as in reducing climate 
change variability's and their impacts all indicated adaptation strategies are not such significant. These districts research findings cannot be generalized to other districts because of some regional, environmental and socioeconomic disparities.

\section{Declarations}

Ethical Approval

Ethical approval taken from the COMSATS University Vehari campus, ethical approval committee

Consent to Participate

Not applicable

Consent to Publish

Not applicable

Authors Contributions

DA analyzed data, methodology, results and discussion, conclusion and suggestions and manuscript write up whereas both DA and MA finalized and proof read the manuscript and both authors read and approved the final manuscript.

Funding

This study has no funding from any institution or any donor agency.

Competing Interests

The authors declare that they have no competing interest.

Availability of data and materials

The datasets used and/or analyzed during the current study are available from the corresponding author on reasonable request.

\section{References}

1. Abid M, Ali A, Raza M, Mehdi M (2020) Ex-ante and ex-post coping strategies for climatic shocks and adaptation determinants in rural Malawi. Climate Risk Management 27:100200

2. Abid M, Scheffran J, Schneider UA, Ashfaq MJESD (2015) Farmers' perceptions of and adaptation strategies to climate change and their determinants: the case of Punjab province, Pakistan. Earth Sys Dyn 6(1):225-243

3. Abid M, Scheffran J, Schneider UA, Elahi E (2019) Farmer perceptions of climate change, observed trends and adaptation of agriculture in Pakistan. Environ Manage 63(1):110-123

4. Abid M, Schilling J, Scheffran J, Zulfiqar F (2016) Climate change vulnerability, adaptation and risk perceptions at farm level in Punjab, Pakistan. Sci Total Environ 547:447-460

5. Adger WN, Agrawal S, Mirza MMW, Conde C, O'brien KL, Pulhin J, Takahashi K (2007) Assessment of adaptation practices, options, constraints and capacity. Climate change 2007: impacts, adaptation and vulnerability. Contribution of working group II to the fourth assessment report of the Intergovernmental Panel on Climate Change. Cambridge University Press, pp 719-743

6. Adger WN, Dessai S, Goulden M, Hulme M, Lorenzoni I, Nelson DR, Wreford A (2009) Are there social limits to adaptation to climate change? Clim Change 93(3):335-354

7. Aggarwal PK, Sivakumar MV (2010) Global climate change and food security in South Asia: An adaptation and mitigation framework. Climate change and food security in South Asia. Springer, Dordrecht, pp 253-275

8. Ahmad D, Afzal M (2020) Climate change adaptation impact on cash crop productivity and income in Punjab province of Pakistan. Environ Sci Pollut Res 27:30767-30777

Page $11 / 23$ 
9. Ahmad D, Afzal M (2021) Flood hazards, human displacement and food insecurity in rural riverine areas of Punjab, Pakistan: policy implications. Environ Sci Pollut Res 28(8):10125-10139

10. Ahmad D, Afzal M (2021) Impact of climate change on pastoralists' resilience and sustainable mitigation in Punjab, Pakistan.Environment, Development and Sustainability,1-21

11. Ahmad D, Afzal M, Rauf A (2019) Analysis of wheat farmers' risk perceptions and attitudes: evidence from Punjab, Pakistan. Nat Hazards 95(3):845-861

12. Ahmad I, Ahmad B, Boote K, Hoogenboom G (2020) Adaptation strategies for maize production under climate change for semiarid environments. Eur J Agron 115:126040

13. Alam GM, Alam K, Mushtaq S (2017) Climate change perceptions and local adaptation strategies of hazard-prone rural households in Bangladesh. Climate Risk Management 17:52-63

14. Alauddin M, Sarker MAR (2014) Climate change and farm-level adaptation decisions and strategies in drought-prone and groundwater-depleted areas of Bangladesh: an empirical investigation. Ecol Econ 106:204-213

15. Ali A, Abdulai A (2010) The adoption of genetically modified cotton and poverty reduction in Pakistan. J Agric Econ 61(1):175192

16. Ali A, Erenstein $O$ (2017) Assessing farmer use of climate change adaptation practices and impacts on food security and poverty in Pakistan. Climate Risk Management 16:183-194

17. Ali S, Liu Y, Ishaq M, Shah T, llyas A, Din IU (2017) Climate change and its impact on the yield of major food crops: Evidence from Pakistan. Foods 6(6):39

18. Amare A, Simane B (2018) Does adaptation to climate change and variability provide household food security? Evidence from Muger sub-basin of the upper Blue-Nile, Ethiopia. Ecological processes 7(1):1-12

19. Amare ZY, Ayoade JO, Adelekan IO, Zeleke MT (2018) Barriers to and determinants of the choice of crop management strategies to combat climate change in Dejen District, Nile Basin of Ethiopia. Agriculture \& Food Security 7(1):1-11

20. Arfanuzzaman M, Hassan ST, Syed MA (2021) Cost-benefit of promising adaptations for resilient development in climate hotspots: evidence from lower Teesta basin in Bangladesh. Journal of Water and Climate Change 12(1):44-59

21. Arif M, Jan T, Munir H, Rasul F, Riaz M, Fahad S, Mian IA (2020) Climate-smart agriculture: assessment and adaptation strategies in changing climate. Global Climate Change and Environmental Policy. Springer, Singapore, pp 351-377

22. Arunrat N, Wang C, Pumijumnong N, Sereenonchai S, Cai W (2017) Farmers' intention and decision to adapt to climate change: A case study in the Yom and Nan basins, Phichit province of Thailand. J Clean Prod 143:672-685

23. Bawakyillenuo S, Yaro JA, Teye J (2016) Exploring the autonomous adaptation strategies to climate change and climate variability in selected villages in the rural northern savannah zone of Ghana. Local Environ 21(3):361-382

24. Bokhari SAA, Ahmad B, Ali J, Ahmad S, Mushtaq H, Rasul G (2018) Future climate change projections of the Kabul River Basin using a multi-model ensemble of high-resolution statistically downscaled data. Earth Systems and Environment 2(3):477-497

25. Punjab BOS (2019) Agricultural statistics 2019, Bureau of Statistics Punjab. Government of Punjab, Pakistan

26. Punjab BOS (2020) Agricultural statistics 2020, Bureau of Statistics Punjab. Government of Punjab, Pakistan

27. Punjab BOS (2021) Agricultural statistics 2021, Bureau of Statistics Punjab. Government of Punjab, Pakistan

28. Bryan E, Ringler C, Okoba B, Roncoli C, Silvestri S, Herrero M (2013) Adapting agriculture to climate change in Kenya: Household strategies and determinants. J Environ Manage 114:26-35

29. Caliendo M, Kopeinig S (2008) Some practical guidance for the implementation of propensity score matching. J Economic Surveys 22(1):31-72

30. Chalise S, Naranpanawa A (2016) Climate change adaptation in agriculture: A computable general equilibrium analysis of landuse change in Nepal. Land use policy 59:241-250

31. Chen S, Gong B (2021) Response and adaptation of agriculture to climate change: evidence from China. J Dev Econ 148:102557

32. Crane TA, Delaney A, Tamás PA, Chesterman S, Ericksen P (2017) A systematic review of local vulnerability to climate change in developing country agriculture.Wiley Interdisciplinary Reviews: Climate Change, 8(4), e464 
33. Cui X (2020) Climate change and adaptation in agriculture: Evidence from US cropping patterns. J Environ Econ Manag 101:102306

34. Daniell JE, Daniell TM, Daniell KA, Wenzel F, Schäfer AM, Kunz M, Burford R (2017, April) Wine: the increasing risk of a highly vulnerable industry globally to natural disasters and climate change (NH Division Outstanding ECS Award Lecture). In EGU General Assembly Conference Abstracts (p. 2315)

35. Day E, Fankhauser S, Kingsmill N, Costa H, Mavrogianni A (2019) Upholding labour productivity under climate change: an assessment of adaptation options. Clim Policy 19(3):367-385

36. Dehejia RH, Wahba S (2002) Propensity score-matching methods for nonexperimental causal studies. Rev Econ Stat 84(1):151-161

37. Demski C, Capstick S, Pidgeon N, Sposato RG, Spence A (2017) Experience of extreme weather affects climate change mitigation and adaptation responses. Clim Change 140(2):149-164

38. Duarte CM, Losada IJ, Hendriks IE, Mazarrasa I, Marbà N (2013) The role of coastal plant communities for climate change mitigation and adaptation. Nature Climate Change 3(11):961-968

39. Eckstein D, Hutfils ML, Winges M (2018) Global climate risk index 2019. Germanwatch: Bonn, Germany

40. Eckstein D, Künzel V, Schäfer L, Winges M (2019) Global climate risk index 2020. Bonn: Germanwatch

41. FAO (2019) Most wheat producing countries of the world. Food and Agriculture Organization

42. Froehlich P, Al-Saidi M (2017) Community-based adaptation to climate change in Egypt-status quo and future policies. Climate Change Research at Universities. Springer, Cham, pp 235-250

43. Frölich M (2007) Propensity score matching without conditional independence assumption-with an application to the gender wage gap in the United Kingdom. The Econometrics Journal 10(2):359-407

44. Giri S, Lathrop RG, Obropta CC (2020) Climate change vulnerability assessment and adaptation strategies through best management practices. J Hydrol 580:124311

45. GOP (2021) Economic survey of Pakistan 2021. Ministry of Finance Division Islamabad, Government of Pakistan

46. Heckman JJ, Vytlacil EJ (2007) Econometric evaluation of social programs, part I: Causal models, structural models and econometric policy evaluation. Handbook of econometrics 6:4779-4874

47. Hoq MS, Raha SK, Hossain MI (2021) Livelihood vulnerability to flood hazard: Understanding from the flood-prone haor ecosystem of Bangladesh. Environ Manage 67(3):532-552

48. Hou D, Song Y, Zhang J, Hou M, O'Connor D, Harclerode M (2018) Climate change mitigation potential of contaminated land redevelopment: A city-level assessment method. J Clean Prod 171:1396-1406

49. Huang J, Wang Y, Wang J (2015) Farmers' adaptation to extreme weather events through farm management and its impacts on the mean and risk of rice yield in China. Am J Agric Econ 97(2):602-617

50. Huong NTL, Yao S, Fahad S (2019) Assessing household livelihood vulnerability to climate change: The case of Northwest Vietnam. Human and Ecological Risk Assessment: An International Journal 25(5):1157-1175

51. Hussain M, Butt AR, Uzma F, Ahmed R, Rehman A, Ali MU, Yousaf B (2019) Divisional disparities on climate change adaptation and mitigation in Punjab, Pakistan: local perceptions, vulnerabilities, and policy implications. Environ Sci Pollut Res 26(30):31491-31507

52. Iglesias A, Mougou R, Moneo M, Quiroga S (2011) Towards adaptation of agriculture to climate change in the Mediterranean. Reg Envriron Chang 11(1):159-166

53. IPCC (2019) Global Warming of $1.5^{\circ} \mathrm{C}$ Intergovernmental Panel of Climate Change https://www.ipcc.ch/site/assets/uploads/sites/2/2019/06/SR15_Full_Report_High_Res.pdf

54. Islam A, Ghosh S (2021) Community-based riverine flood risk assessment and evaluating its drivers: evidence from Rarh Plains of India.Applied Spatial Analysis and Policy,1-47

55. Jawid A, Khadjavi M (2019) Adaptation to climate change in Afghanistan: Evidence on the impact of external interventions. Econ Anal Policy 64:64-82

56. Jørgensen SL, Termansen M, Pascual U (2020) Natural insurance as condition for market insurance: Climate change adaptation in agriculture. Ecol Econ 169:106489

Page 13/23 
57. Joshi B, Ji W, Joshi NB (2017) Farm households' perception on climate change and adaptation practices: A case from mountain district of Nepal.International Journal of Climate Change Strategies and Management

58. Kabisch N, Frantzeskaki N, Pauleit S, Naumann S, Davis M, Artmann M, Bonn A (2016) Nature-based solutions to climate change mitigation and adaptation in urban areas: perspectives on indicators, knowledge gaps, barriers, and opportunities for action. Ecology and Society, 21(2)

59. Kassie M, Shiferaw B, Muricho G (2011) Agricultural technology, crop income, and poverty alleviation in Uganda. World Dev 39(10):1784-1795

60. Khan AH, Levac E, Van Guelphen L, Pohle G, Chmura GL (2018) The effect of global climate change on the future distribution of economically important macroalgae (seaweeds) in the northwest Atlantic. Facets 3(1):275-286

61. Khan I, Lei H, Shah IA, Ali I, Khan I, Muhammad I, Javed T (2020) Farm households' risk perception, attitude and adaptation strategies in dealing with climate change: promise and perils from rural Pakistan. Land use policy 91:104395

62. Khan MD, Vu T, Lai HH, Ahn JW (2019) Aggravation of human diseases and climate change nexus. Int J Environ Res Public Health 16(15):2799

63. Khanal U, Wilson C, Hoang VN, Lee B (2018) Farmers' adaptation to climate change, its determinants and impacts on rice yield in Nepal. Ecol Econ 144:139-147

64. Khatri-Chhetri A, Pant A, Aggarwal PK, Vasireddy VV, Yadav A (2019) Stakeholders prioritization of climate-smart agriculture interventions: Evaluation of a framework. Agric Syst 174:23-31

65. Kreft C, Huber R, Wuepper D, Finger R (2021) The role of non-cognitive skills in farmers' adoption of climate change mitigation measures. Ecol Econ 189:107169

66. Leclère D, Jayet PA, de Noblet-Ducoudré N (2013) Farm-level autonomous adaptation of European agricultural supply to climate change. Ecol Econ 87:1-14

67. Locatelli B, Pavageau C, Pramova E, Di Gregorio M (2015) Integrating climate change mitigation and adaptation in agriculture and forestry: opportunities and trade-offs. Wiley Interdisciplinary Reviews: Climate Change 6(6):585-598

68. Lucena AF, Hejazi M, Vasquez-Arroyo E, Turner S, Köberle AC, Daenzer K, van der Zwaan B (2018) Interactions between climate change mitigation and adaptation: The case of hydropower in Brazil. Energy 164:1161-1177

69. Mahmood N, Arshad M, Mehmood Y, Shahzad MF, Kächele H (2021) Farmers' perceptions and role of institutional arrangements in climate change adaptation: Insights from rainfed Pakistan. Climate Risk Management 32:100288

70. Martins IM, Gasalla MA (2020) Adaptive Capacity Level Shapes Social Vulnerability to Climate Change of Fishing Communities in the South Brazil Bight. Frontiers in Marine Science 7:481

71. McCarl BA, Schneider UA (2001) Greenhouse gas mitigation in US agriculture and forestry. Science 294(5551):2481-2482

72. McCarl BA, Thayer AW, Jones JP (2016) The challenge of climate change adaptation for agriculture: An economically oriented review. J Agric Appl Econ 48(4):321-344

73. Mersha AA, van Laerhoven $F(2018)$ The interplay between planned and autonomous adaptation in response to climate change: Insights from rural Ethiopia. World Dev 107:87-97

74. Metz B, Davidson O, Bosch P, Dave R, Meyer L (2007) Climate change 2007: Mitigation of climate change. Cambridge Univ. Press

75. Nakashima D, Krupnik I (eds) (2018) Indigenous knowledge for climate change assessment and adaptation, vol 2. Cambridge University Press

76. Nakashima D, Rubis J, Krupnik I (2018) Indigenous knowledge for climate change assessment and adaptation: Introduction. Indigenous knowledge for climate change assessment and adaptation, 1-20

77. NDMA (2019) Annual Report 2019, National Disaster Management Authority Government of Pakistan

78. Nerini FF, Sovacool B, Hughes N, Cozzi L, Cosgrave E, Howells M, Milligan B (2019) Connecting climate action with other Sustainable Development Goals. Nature Sustainability 2(8):674-680

79. Pandey R, Maithani N, Aretano R, Zurlini G, Archie KM, Gupta AK, Pandey VP (2016) Empirical assessment of adaptation to climate change impacts of mountain households: Development and application of an Adaptation Capability Index. J Mt Sci 13(8):1503-1514 
80. PBS (2017) 6th Household and Population survey 2017, Economic survey of Pakistan. Ministry of Finance Government of Pakistan

81. PBS (2020) Economic survey of Pakistan 2020. Ministry of Finance Division Islamabad, Government of Pakistan

82. PBS (2021) Economic survey of Pakistan 2021. Ministry of Finance Division Islamabad, Government of Pakistan

83. PMD (2018) Climate Change Impact. Pakistan Metrological Department Government of Pakistan

84. PMD (2019) Climate Change Impact 2019. Pakistan Metrological Department Government of Pakistan

85. Rahman HM, Hickey GM (2019) What does autonomous adaptation to climate change have to teach public policy and planning about avoiding the risks of maladaptation in Bangladesh? Frontiers in Environmental Science 7:2

86. Rahman HT, Hickey GM, Ford JD, Egan MA (2018) Climate change research in Bangladesh: research gaps and implications for adaptation-related decision-making. Reg Envriron Chang 18(5):1535-1553

87. Rasiah R, Kari F, Sadoi Y, Mintz-Habib N (2018) Climate change and sustainable development issues: arguments and policy initiatives. J Asia Pac Econ 23(2):187-194

88. Rubin DB (2001) Using propensity scores to help design observational studies: application to the tobacco litigation. Health Serv Outcomes Res Method 2(3):169-188

89. Rubin O (2015) The Burden of Excessive "Linking Social Capital": Evidence from Four Vietnamese Provinces. Asian Journal of Social Science 43(6):760-785

90. Schlenker W, Lobell DB (2010) Robust negative impacts of climate change on African agriculture. Environmental Research Letters 5(1):014010

91. Seo SN, Mendelsohn R (2008) An analysis of crop choice: Adapting to climate change in South American farms. Ecol Econ 67(1):109-116

92. Sertse SF, Khan NA, Shah AA, Liu Y, Naqvi SAA (2021) Farm households' perceptions and adaptation strategies to climate change risks and their determinants: Evidence from Raya Azebo district, Ethiopia. International Journal of Disaster Risk Reduction 60:102255

93. Shah AA, Ye J, Shaw R, Ullah R, Ali M (2020) Factors affecting flood-induced household vulnerability and health risks in Pakistan: the case of Khyber Pakhtunkhwa (KP) Province. International Journal of Disaster Risk Reduction 42:101341

94. Siddiqui R, Samad G, Nasir M, Jalil HH (2012) The impact of climate change on major agricultural crops: evidence from Punjab, Pakistan. The Pakistan Development Review,261-274

95. Solan M, Bennett EM, Mumby PJ, Leyland J, Godbold JA (2020) Benthic-based contributions to climate change mitigation and adaptation. Philosophical Transactions of the Royal Society B 375(1794):20190107

96. Teo M, Goonetilleke A, Ahankoob A, Deilami K, Lawie M (2018) Disaster awareness and information seeking behaviour among residents from low socio-economic backgrounds. International journal of disaster risk reduction 31:1121-1131

97. Thaler S, Eitzinger J, Trnka M, Dubrovsky M (2012) Impacts of climate change and alternative adaptation options on winter wheat yield and water productivity in a dry climate in Central Europe. The Journal of Agricultural Science 150(5):537-555

98. Thavaneswaran A, Lix L (2008) Propensity score matching in observational studies. Manitoba Centre for Health Policy,1-28

99. Ullah W, Nihei T, Nafees M, Zaman R, Ali M (2018) Understanding climate change vulnerability, adaptation and risk perceptions at household level in Khyber Pakhtunkhwa, Pakistan.International Journal of Climate Change Strategies and Management

100. Vermeulen SJ, Dinesh D, Howden SM, Cramer L, Thornton PK (2018) Transformation in practice: a review of empirical cases of transformational adaptation in agriculture under climate change. Frontiers in Sustainable Food Systems 2:65

101. World Health Organization (2013) Protecting health from climate change: vulnerability and adaptation assessment. World Health Organization

102. Zhongming Z, Wangqiang Z, Wei L (2012) Weathering uncertainty: traditional knowledge for climate change assessment and adaptation

\section{Tables}

Page $15 / 23$ 
Table 1

Study area sampling framework

\begin{tabular}{|llll|}
\hline Categorizes wheat production areas zone & Study districts & Study sub-districts & Selected respondents \\
\hline Low wheat yield zone & Dera Ghazi Khan & Kot Chutta, Dera Ghazi Khan & 80 \\
\cline { 2 - 4 } (Lower than 600,000 tonnes) & Layyah & Karor Lal Esan, Layyah & 80 \\
\hline Medium wheat yield zone & Muzaffargarh & Alipur, Kot Addu & 80 \\
\cline { 2 - 4 }$(600,000$ to 900,000 tonnes) & Vehari & Malsi, Vehari & 80 \\
\hline High wheat yield zone & Rahim Yar Khan & Khanpur, Sadiqabad & 80 \\
\cline { 2 - 4 } (above 900,000tonnes) & Bahawalnagar & Haroonabad, Chishtian & 80 \\
\hline Grand Total & & & 480 \\
\hline
\end{tabular}


Table 2

Study variables description

\begin{tabular}{|c|c|c|c|}
\hline Variables outcome & Description of variables & & Types of variables \\
\hline Wheat yield & Per acre maunds ${ }^{1}$ & & Continuous \\
\hline Total wheat return & Wheat crop total return in PKRs ${ }^{2}$ (thousands) & & Continuous \\
\hline Cost of inputs & Inputs total cost per acre $\mathrm{PKRs}^{3}$ (thousands) & & Continuous \\
\hline Explanatory variables & Description of variables & Types of variables & $\begin{array}{l}\text { Expected sign of } \\
\text { variables }\end{array}$ \\
\hline Age of farmers & Age in years & $\begin{array}{l}\text { Continuous } \\
\text { variable }\end{array}$ & \pm \\
\hline Education of farmers & Schooling in years & $\begin{array}{l}\text { Continuous } \\
\text { variable }\end{array}$ & + \\
\hline Size of households & Number of household head members & $\begin{array}{l}\text { Continuous } \\
\text { variable }\end{array}$ & \pm \\
\hline $\begin{array}{l}\text { Occupation primary } \\
\text { level }\end{array}$ & Farming $=1$ otherwise $=0$ & Dummy variable & \pm \\
\hline Size of landholding & Acres in numbers & $\begin{array}{l}\text { Continuous } \\
\text { variable }\end{array}$ & + \\
\hline Ownership of land & Farmer owner $=1$ otherwise $=0$ & Dummy variable & \pm \\
\hline Ownership of tubewell & Farmer own tubewell= 1 otherwise $=0$ & Dummy variable & + \\
\hline Land canal irrigated & Percentage irrigated by canal water & $\begin{array}{l}\text { Continuous } \\
\text { variable }\end{array}$ & + \\
\hline Holding livestock & Animals numbers & $\begin{array}{l}\text { Continuous } \\
\text { variable }\end{array}$ & + \\
\hline Income of farm & PKRs in thousands & $\begin{array}{l}\text { Continuous } \\
\text { variable }\end{array}$ & + \\
\hline Labor of farm & Number of labor at farm activity & $\begin{array}{l}\text { Continuous } \\
\text { variable }\end{array}$ & \pm \\
\hline $\begin{array}{l}\text { Income at off-farm } \\
\text { level }\end{array}$ & PKRs in thousands & $\begin{array}{l}\text { Continuous } \\
\text { variable }\end{array}$ & \pm \\
\hline Advisory at farm level & Advisory received by farmer $=1$ otherwise $=0$ & Dummy variable & + \\
\hline Services of credit & Credit utilized by farmer $=1$ otherwise $=0$ & Dummy variable & \pm \\
\hline Information of climate & $\begin{array}{l}\text { Climate information access by farmer }=1 \text { otherwise } \\
=0\end{array}$ & Dummy variable & + \\
\hline \multicolumn{4}{|c|}{${ }^{1}$ Wheat measuring unit ( 1 maund $=40 \mathrm{~kg}$ ) } \\
\hline \multicolumn{4}{|c|}{${ }^{2}$ Pakistan's land unit ( 1 hectare $=2.47$ acre $)$} \\
\hline${ }^{3} \mathrm{PKRs}=$ when survey $\mathrm{c}$ & ed out in $2020,1 \$=166.23 \mathrm{PKRs}$ & & \\
\hline
\end{tabular}


Table 3

Adapter and non-adapter farmers' comparison mean value

\begin{tabular}{|c|c|c|c|c|c|c|c|}
\hline \multirow[t]{2}{*}{ Study variables } & \multicolumn{2}{|c|}{ Adapter farmers (374) } & \multicolumn{2}{|c|}{$\begin{array}{l}\text { Non-adapter farmers } \\
\text { (106) }\end{array}$} & \multirow{2}{*}{$\begin{array}{l}\text { Difference } \\
\text { (non-adapter- } \\
\text { adapter) }\end{array}$} & \multicolumn{2}{|c|}{ Pooled sample (480) } \\
\hline & $\begin{array}{l}\text { Mean } \\
\text { value }\end{array}$ & $\begin{array}{l}\text { Standard } \\
\text { deviation }\end{array}$ & $\begin{array}{l}\text { Mean } \\
\text { value }\end{array}$ & $\begin{array}{l}\text { Standard } \\
\text { deviation }\end{array}$ & & $\begin{array}{l}\text { Mean } \\
\text { value }\end{array}$ & $\begin{array}{l}\text { Standard } \\
\text { deviation }\end{array}$ \\
\hline $\begin{array}{l}\text { Wheat yield (maund }{ }^{1} \\
\text { per acre) }\end{array}$ & 58.79 & 7.354 & 49.36 & 6.326 & -9.43 & 54.075 & 6.987 \\
\hline $\begin{array}{l}\text { Return of wheat per } \\
\text { acre (PKRs) }\end{array}$ & 43.76 & 6.465 & 34.62 & 5.287 & -9.14 & 39.19 & 5.975 \\
\hline Input const & 38.54 & 5.651 & 32.47 & 4.941 & -6.07 & 35.505 & 5.921 \\
\hline Age of farmers & 45.27 & 10.67 & 50.91 & 11.99 & -1.76 & 48.09 & 12.04 \\
\hline Education of farmers & 8.14 & 4.99 & 6.47 & 3.74 & -1.33 & 7.11 & 4.72 \\
\hline Size of households & 8.02 & 5.23 & 6.84 & 4.58 & -0.78 & 7.43 & 4.87 \\
\hline $\begin{array}{l}\text { Occupation primary } \\
\text { level }\end{array}$ & 0.889 & 0.361 & 0.613 & 0.489 & -0.276 & 0.751 & 0.386 \\
\hline Size of landholding & 8.97 & 6.452 & 5.67 & 4.64 & -3.3 & 7.32 & 5.89 \\
\hline Ownership of land & 0.968 & 0.296 & 0.843 & 0.387 & -0.125 & 0.9055 & 0.281 \\
\hline Ownership of tubewell & 0.891 & 0.453 & 0.327 & 0.413 & -0.564 & 0.609 & 0.457 \\
\hline Land canal irrigated & 18.76 & 14.764 & 8.654 & 11.342 & -10.106 & 13.707 & 11.541 \\
\hline Holding livestock & 7.541 & 4.032 & 4.321 & 3.154 & -3.22 & 5.931 & 4.167 \\
\hline Income of farm & 48.572 & 28.487 & 24.853 & 20.359 & -23.715 & 36.7125 & 25.431 \\
\hline Labor of farm & 3.487 & 1.758 & 1.976 & 1.367 & -1.511 & 2.7315 & 1.876 \\
\hline $\begin{array}{l}\text { Income at off-farm } \\
\text { level }\end{array}$ & 12.876 & 11.041 & 10.897 & 10.117 & -1.979 & 11.8865 & 10.754 \\
\hline Advisory at farm level & 0.764 & 0.543 & 0.379 & 1.342 & -0.395 & 0.5715 & 0.4891 \\
\hline Services of credit & 0.589 & 0.498 & 0.134 & 0.121 & -0.455 & 0.3615 & 0.431 \\
\hline Information of climate & 0.843 & 0.573 & 0.349 & 0.231 & -0.494 & 0.596 & 0.376 \\
\hline
\end{tabular}


Table 4

Estimates of Propensity Score Matching by application of Probit regression

\begin{tabular}{|lllll|}
\hline Independent variables & Coefficient of variables & Standard error & P>Z & Marginal effect \\
\hline Age of farmers & 0.014 & 0.21 & 0.617 & 0.0019 \\
\hline Education of farmers & 0.023 & 0.047 & 0.769 & 0.0020 \\
\hline Size of households & 0.196 & 0.112 & 0.178 & 0.0224 \\
\hline Occupation primary level & 0.897 & 0.365 & 0.026 & 0.1267 \\
\hline Size of landholding & 0.194 & 0.113 & 0.081 & 0.0275 \\
\hline Ownership of land & -0.041 & 0.367 & 0.875 & -0.0039 \\
\hline Ownership of tubewell & 1.342 & 0.263 & 0.001 & 0.1932 \\
\hline Land canal irrigated & 0.037 & 0.017 & 0.006 & 0.0049 \\
\hline Holding livestock & 0.197 & 0.084 & 0.028 & 0.0298 \\
\hline Income of farm & -0.063 & 0.032 & 0.037 & -0.0091 \\
\hline Labor of farm & -0.024 & 0.198 & 0.897 & -0.0026 \\
\hline Income at off-farm level & 0.0386 & 0.028 & 0.048 & 0.0063 \\
\hline Advisory at farm level & 1.698 & 0.494 & 0.002 & 0.2784 \\
\hline Services of credit & 1.795 & 0.736 & 0.009 & 0.2478 \\
\hline Information of climate & 0.243 & 0.271 & 0.452 & 0.0354 \\
\hline Constant & -4.137 & 1.243 & 0.001 & \\
\hline LR ${ }^{2}$ (16) = 234.721 & & Log likelihood $=-79243$ & \\
\hline Prob $>\chi^{2}=0.000$ & & & & \\
\hline Observations numbers $=480$ & & & & \\
\hline
\end{tabular}

Table 5

Adaptation casual effect on wheat crop yield and return

\begin{tabular}{|lllll|}
\hline Outcome variable & Type of sample & \multicolumn{1}{c|}{$\begin{array}{l}\text { Treated } \\
\text { (adapter) }\end{array}$} & $\begin{array}{l}\text { Controls } \\
\text { (non-adapter) }\end{array}$ & Difference \\
\hline Wheat yield (maunds per acre) & $\begin{array}{l}\text { Unmatched (Average Treatment } \\
\text { Effect in population (ATE)) }\end{array}$ & 58.79 & 49.36 & $\begin{array}{l}9.43(931.684 \mathrm{~kg} \\
\text { per hectares) }\end{array}$ \\
\cline { 2 - 4 } & $\begin{array}{l}\text { Matched (Average Treatment effect in } \\
\text { Treated (ATT) }\end{array}$ & 54.38 & 51.24 & $\begin{array}{l}3.14(310.232 \mathrm{~kg} \\
\text { per hectares) }\end{array}$ \\
\hline $\begin{array}{l}\text { Wheat crop total returns } \\
\text { (thousands PKRs per acre) }\end{array}$ & $\begin{array}{l}\text { Unmatched (Average Treatment } \\
\text { Effect in population (ATE)) }\end{array}$ & 114.64 & 96.252 & $\begin{array}{l}18.39(\text { US\$278.41 } \\
\text { per hectares) }\end{array}$ \\
\hline $\begin{array}{l}\text { Matched (Average Treatment effect in } \\
\text { Treated (ATT) }\end{array}$ & 106.841 & 99.918 & $\begin{array}{l}\text { 6.92(US\$82.75 per } \\
\text { hectares) }\end{array}$ \\
\hline
\end{tabular}


Table 6

Balancing covariates before and after matching

\begin{tabular}{|lll|}
\hline Indicators & Before matching & After matching \\
\hline Pseudo ${ }^{2}$ & 0.3987 & 0.089 \\
\hline p>chi2 & 0.000 & 0.573 \\
\hline LR chi2 & 234.16 & 13.47 \\
\hline Median Bias & 59.1 & 7.8 \\
\hline Mean Bias & 64.3 & 10.2 \\
\hline R & $4.76^{\text {a }}$ & 0.98 \\
\hline B & $235.1^{\text {a }}$ & $67.3^{\text {a }}$ \\
\hline Percentage of Var & 64 & 21 \\
\hline aif R is outside the $(0.5 ; 2), B>25 p e r c e n t$ \\
\hline
\end{tabular}

Table 7

Propensity scores evaluation

\begin{tabular}{|c|c|c|c|c|c|c|c|}
\hline \multirow[t]{2}{*}{ Explanatory variables } & \multicolumn{4}{|l|}{ Means } & \multicolumn{2}{|c|}{ t-tests } & \multirow[t]{2}{*}{$\mathrm{V}(\mathrm{T}) / \mathrm{V}(\mathrm{C})$} \\
\hline & Treated & Control & $\begin{array}{l}\text { Percentage } \\
\text { bias }\end{array}$ & $\begin{array}{l}\text { Percentage bias } \\
\text { reduction }\end{array}$ & $t$ & $p>|t|$ & \\
\hline Age of farmers & 51.674 & 50.247 & 7.1 & 19.3 & 0.41 & $(0.697)$ & 1.56 \\
\hline Education of farmers & 6.238 & 6.732 & -1.43 & 89.53 & -0.07 & $(0.876)$ & 1.59 \\
\hline Size of households & 7.248 & 7.021 & 2.38 & 91.67 & 0.11 & $(0.843)$ & $1.87^{\mathrm{a}}$ \\
\hline $\begin{array}{l}\text { Occupation primary } \\
\text { level }\end{array}$ & 0.84 & 0.79 & 6.8 & 89.34 & 0.39 & $(0.731)$ & 0.69 \\
\hline Size of landholding & 6.054 & 5.642 & 3.9 & 88.97 & 0.41 & $(0.691)$ & - \\
\hline Ownership of land & 0.874 & 0.7931 & 19.75 & 20.86 & 0.96 & $(0.357)$ & - \\
\hline Ownership of tubewell & 0.685 & 0.397 & 36.8 & 76.64 & 1.76 & 1.29 & - \\
\hline Land canal irrigated & 10.451 & 11.876 & -7.8 & 86.23 & -0.48 & 0.621 & - \\
\hline Holding livestock & 5.753 & 4.234 & 18.76 & 67.21 & 1.37 & 0.148 & 1.36 \\
\hline Income of farm & 29,547 & 25,786 & 4.9 & 89.6 & 0.49 & 0.497 & 1.52 \\
\hline Labor of farm & 3.46 & 2.79 & -11.83 & 74.65 & -0.59 & 0.47 & 0.89 \\
\hline Income at off-farm level & 7.986 & 9.324 & -12.6 & 23.6 & -0.67 & 0.432 & 1.44 \\
\hline Advisory at farm level & 0.0843 & 0.11542 & -8.7 & 91.54 & -0.59 & 0.493 & $0.46^{a}$ \\
\hline Services of credit & 0.0563 & 0.0834 & -18.6 & 79.6 & -1.98 & 0.038 & - \\
\hline Information of climate & 0.4751 & 0.3426 & 7.9 & 81.43 & 1.49 & 0.176 & 1.22 \\
\hline
\end{tabular}

\section{Figures}




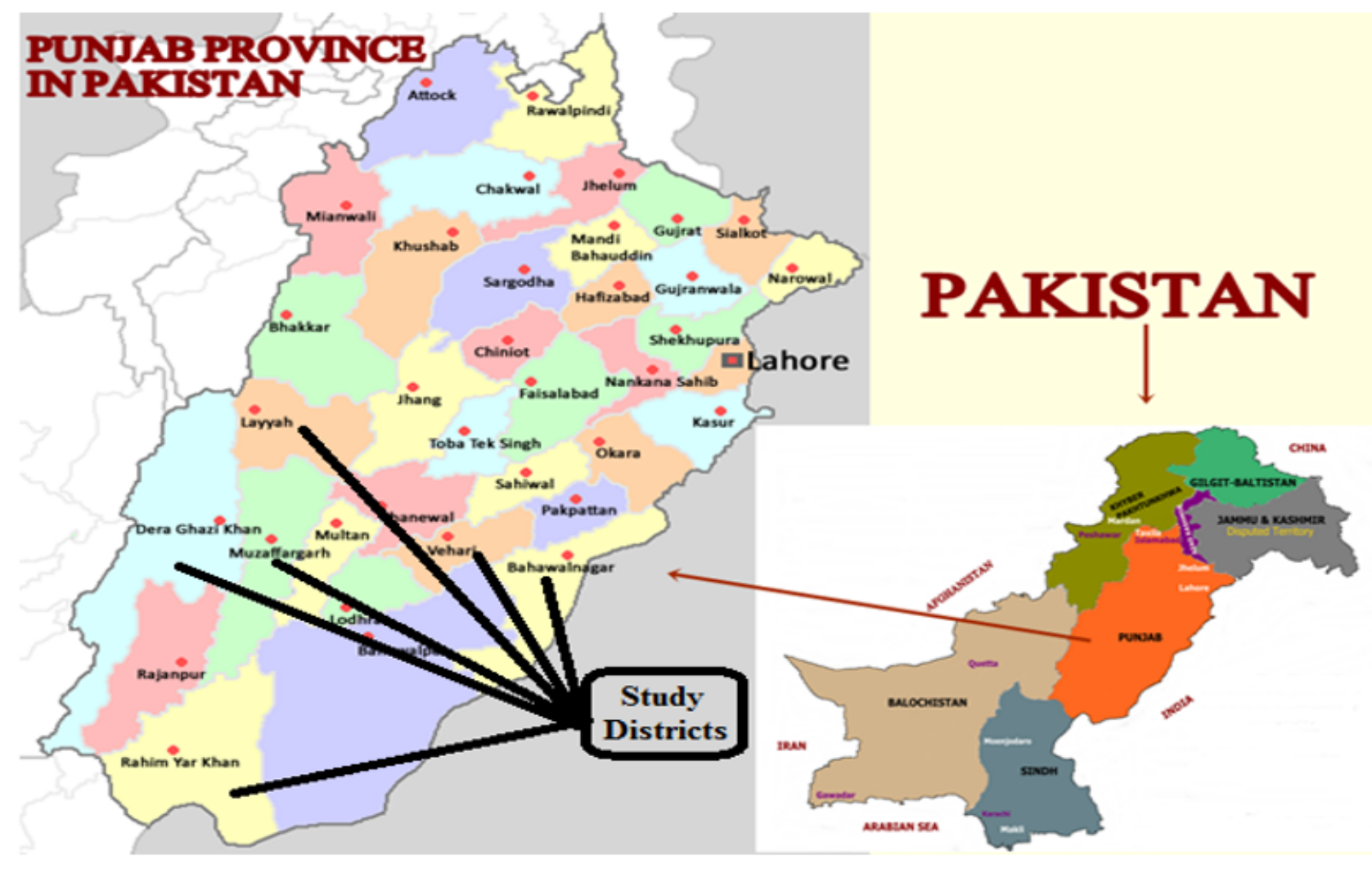

Figure 1

Map of study area districts of Punjab Pakistan

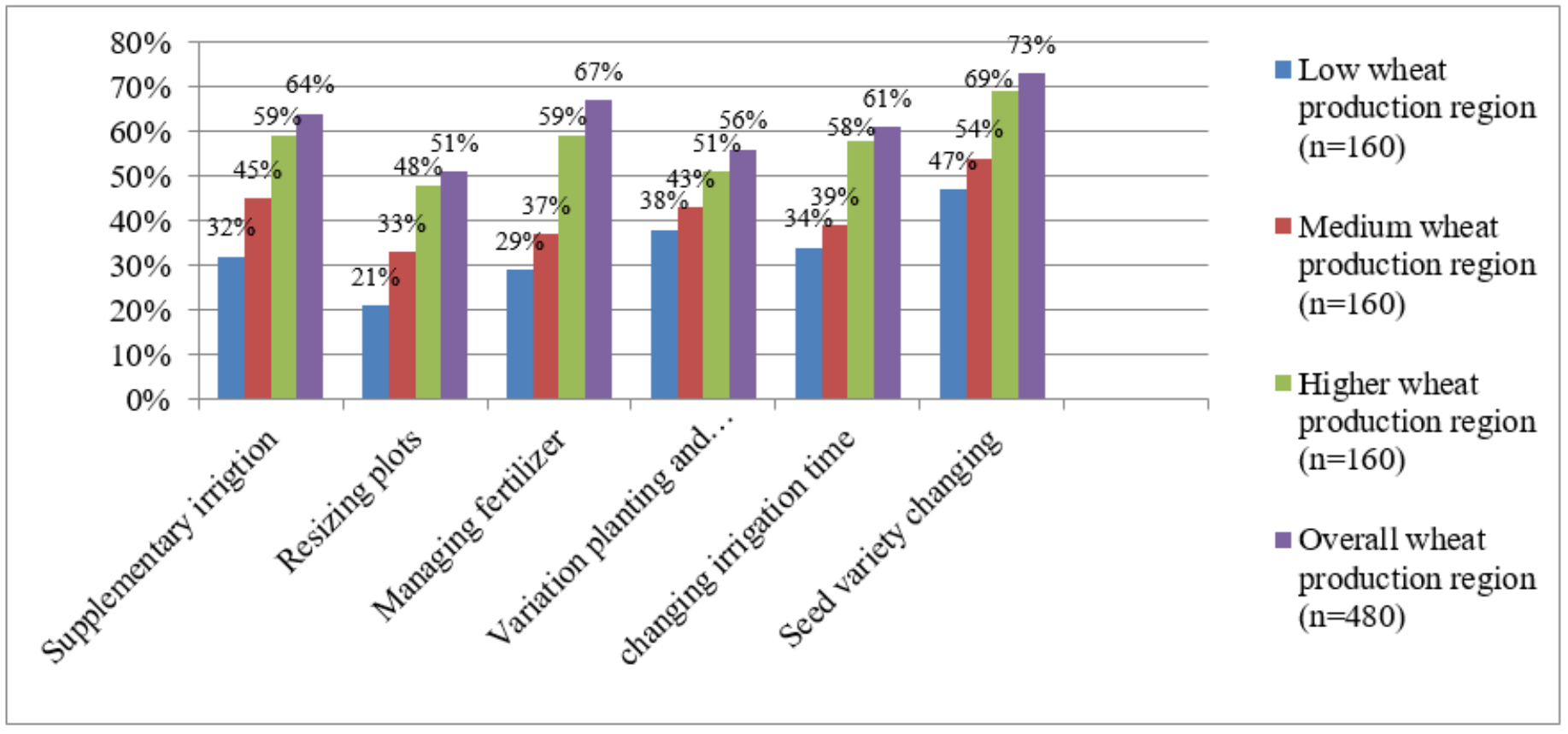

Figure 2

Climate change farmers adapted OFAA strategies 


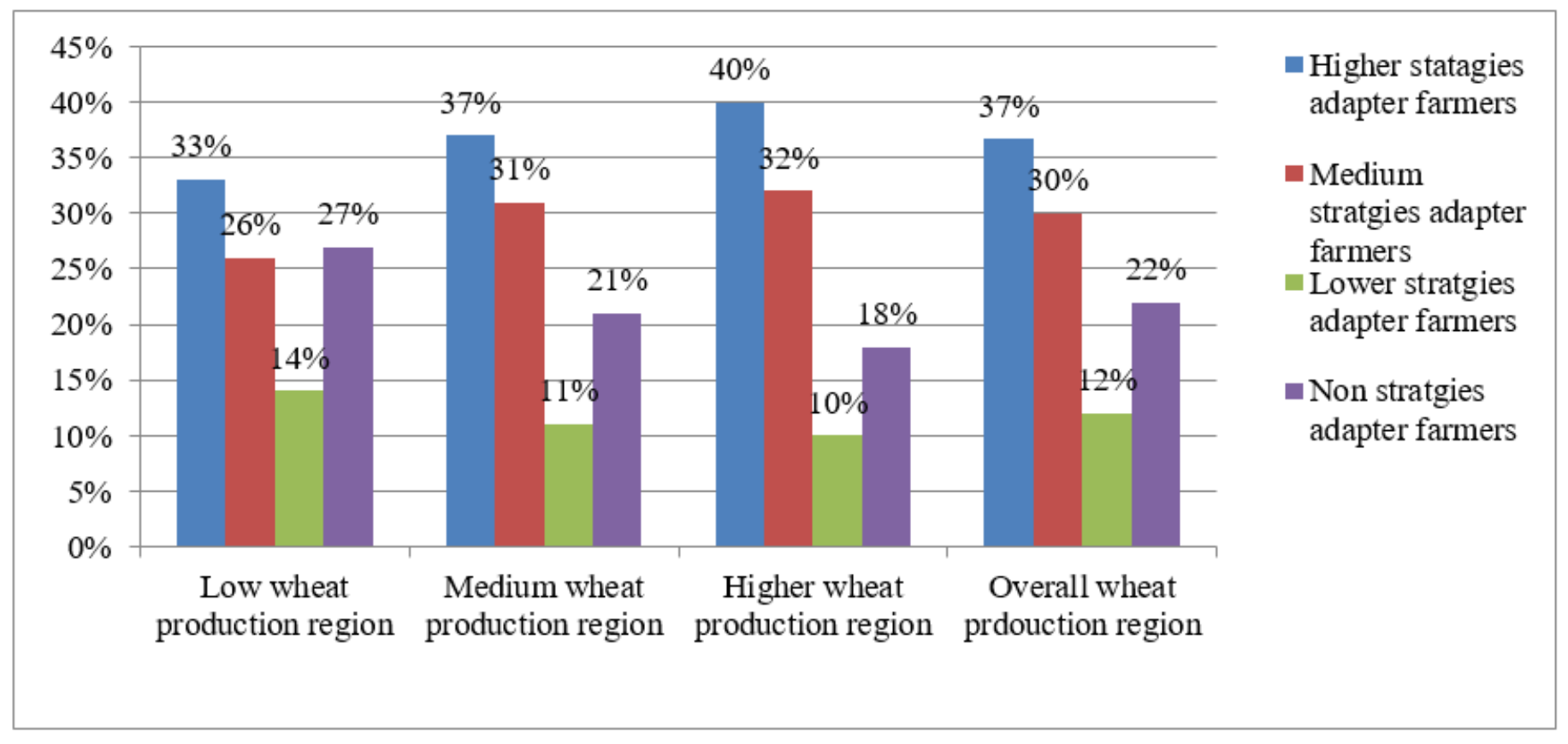

\section{Figure 3}

climate change adaptation classification in the region

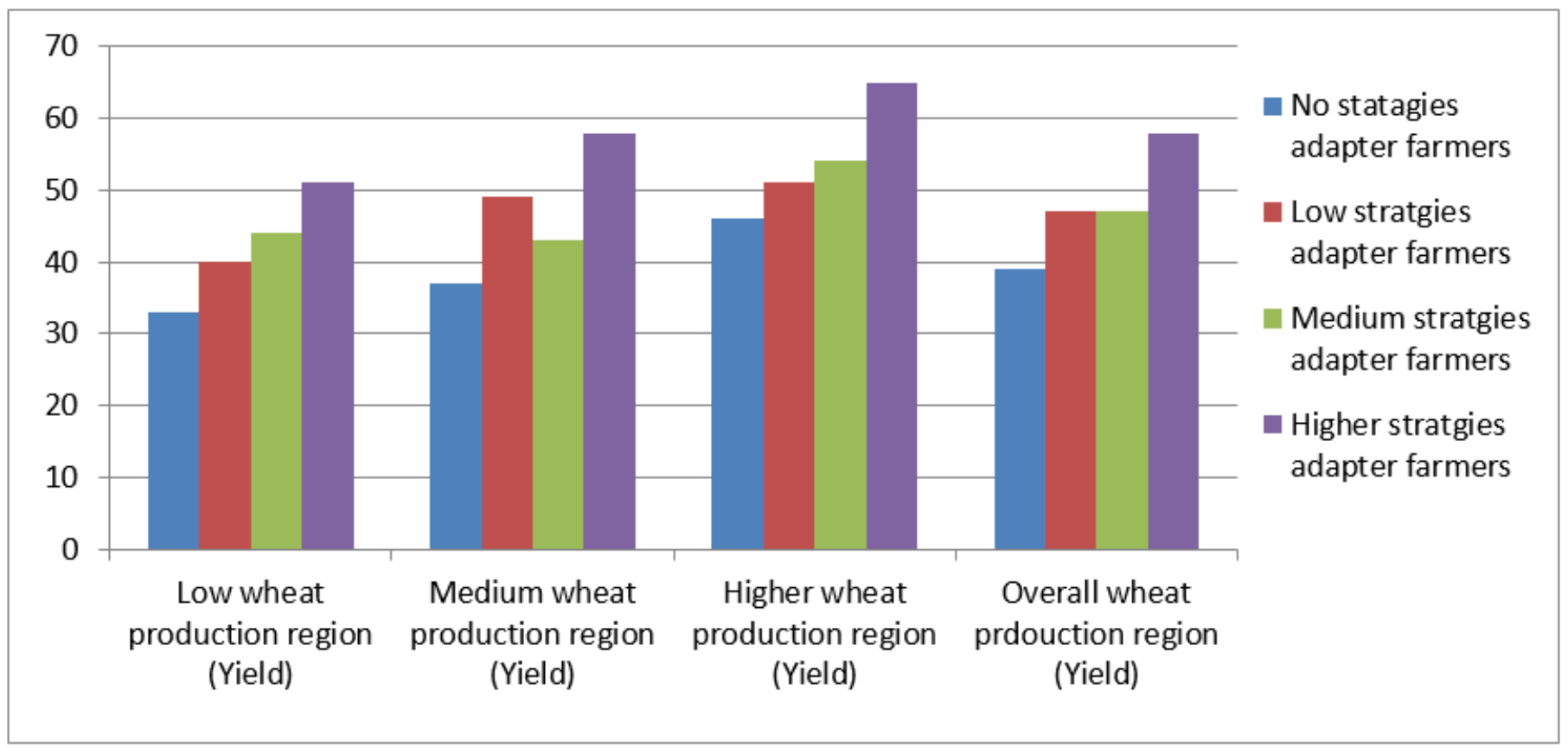

Figure 4

Climate change adaptation intensity its impact on wheat yield 




Figure 5

Climate change adaptation intensity its impact on wheat total wheat return in PKRs 